\title{
Em busca da relação (im)possível: entre a educação literária e a educação artística ${ }^{1}$
}

\section{In search of the (im)possible relationship: between literary education and arts education}

\author{
Mafalda Franco* \\ Ângela Balça*
}

\begin{abstract}
RESUMO
Este estudo aborda a relação entre literatura infantil e expressões artísticas na escola; entre a educação literária e a educação artística. Os principais objetivos do estudo foram: dar a conhecer autores, ilustradores e textos de literatura para a infância; promover a formação do leitor literário; promover às crianças a relação entre a literatura e as expressões artísticas; promover a formação cultural e artística das crianças. Para este estudo convocamos a metodologia da investigação-ação e ele foi desenvolvido com crianças que frequentavam o $2{ }^{\circ}$ ano do ensino básico. Os resultados do estudo permitiram-nos concluir que um trabalho que relacione, na escola, a literatura para a infância e as expressões artísticas proporciona às crianças o prazer e o gosto pela leitura; estimula a imaginação e a criatividade; desenvolve a construção de um leitor crítico; possibilita o estabelecimento de relações entre o texto literário, as ilustrações e as expressões artísticas.

Palavras-chave: Literatura infantil. Expressões artísticas. Escola. Educação literária. Educação artística.
\end{abstract}

1 Esta obra foi financiada por Fundos Nacionais através da FCT (Fundação para a Ciência e a Tecnologia) e cofinanciado pelo Fundo Europeu de Desenvolvimento Regional (FEDER) através do COMPETE 2020 - Programa Operacional Competitividade e Internacionalização (POCI) no âmbito do CIEC (Centro de Investigação em Estudos da Criança da Universidade do Minho) com a referência POCI-01-0145-FEDER-007562.

* Universidade de Évora, Largo dos Colegiais, 2, 7004-516 Évora, Portugal. E-mail: mafaldafranco@sapo.pt.https://orcid.org/0000-0001-8131-2273.E-mail:apb@uevora.pt.https://orcid. org/0000-0002-4159-7718. 


\begin{abstract}
This study deals with the relationship between children's literature and artistic expressions; between literary education and arts education. The main objectives of the study were: knowing authors, illustrators and children's literature texts; promoting the literary reader training; promoting, in children, the relation between literature and artistic expressions; promoting the cultural and artistic training of children. For this study we called the action-research methodology and the study was developed with children who attended the $2^{\text {nd }}$ year of primary school. The results of this study allowed us to conclude that a work that relates, in school, children's literature and artistic expressions gives children pleasure in reading; stimulates imagination and creativity; develops the construction of a critical reader; makes possible the establishment of relations between the literary text, the illustrations and the artistic expressions.
\end{abstract}

Keywords: children's literature, arts expressions, school, literary education, arts education.

\title{
Introdução
}

Neste estudo damos conta de uma investigação-ação realizada com crianças que frequentavam o $1 .^{\circ}$ ciclo do ensino básico $\left(1 .^{\circ} \mathrm{CEB}\right)^{2}$, em redor da relação entre a literatura e as expressões artísticas, com o objetivo de promover, nos leitores mais novos, não só uma educação literária, mas também uma educação artística. Muito embora no sistema educativo português existam programas oficiais para a área da língua portuguesa, que integram a literatura e a educação literária, e para a área das expressões, nomeadamente as expressões plástica, dramática, musical e físico-motora, é um fato que a articulação entre essas duas áreas do currículo é praticamente nula. Acresce que se a área da língua portuguesa é uma constante na práxis dos docentes, abordando-se o texto literário, independentemente das práticas em seu redor, já a área das expressões é completamente relegada para um patamar inferior, estando mesmo ausente em muitas das salas de aulas. Assim, esperamos que este estudo possa dar um contributo para a articulação entre essas duas áreas do currículo.

2 No sistema educativo português, o $1 .^{\circ}$ ciclo do ensino básico compreende do $1 .^{\circ}$ ao $4 .^{\circ}$ ano de escolaridade, tendo as crianças principalmente entre 6 e 10 anos. Corresponderá, no sistema educativo brasileiro, a uma parte inicial do ensino fundamental. 
Desde a implementação do Plano Nacional de Leitura ${ }^{3}$, iniciado em 2006, que a presença do livro de literatura infantil na escola, e mesmo na sala de aula, é uma realidade. Todavia é também uma realidade na sala de aula a onipresença dos manuais escolares, muito estereotipados, que impedem o contato efetivo dos alunos com textos autênticos, ricos e motivadores, de acordo com os seus interesses e necessidades.

O trabalho efetivo com e sobre aliteratura, como produto cultural de elevada qualidade, proporciona às crianças um ambiente rico e estimulante, incrementa o seu interesse pela leitura e pelas práticas de letramento, permite desenvolver o saber acerca do mundo, bem como o conhecimento de diferentes estruturas linguísticas.Como afirma Teresa Colomer, numa entrevista concedida a Castro(2001, p. 2):

Aprender a leer literatura supone leer muchos libros. La explicitación de las reglas, de las convenciones que rigen la obra literaria, permite leer libros más complejos o de una manera más compleja, más rica e inteligente.

Aguiar e Silva (2004) salienta que o texto literário, enquanto artefacto, caracterizado por um conjunto de letras, palavras, enunciados, parágrafos, capítulos, cantos, não produz significado por si só, pois

Os significados não estão no texto [...] Os significados do texto literário é(são) produzido(s) na transação do leitor com o texto, no diálogo que se estabelece entre o leitor e o texto, no jogo das perguntas que o leitor formula ao texto e das respostas que o texto vai proporcionando ao leitor (AGUIAR; SILVA, 2004, p. 91).

Assim, o texto não se limita a uma única leitura, uma única voz, e deve ter em conta a sua própria natureza. Os alunos devem ser incentivados a procurar diferentes sentidos, mobilizar conhecimentos prévios. Lerliteratura implica relações com outros textos e outras vozes. Só assim, de acordo com Azevedo (2006), os alunos podem ser capazes de opinar, selecionar, problematizar, construindo enfim a sua autonomia como leitores.

3 O Plano Nacional de Leitura é uma iniciativa do governo português e trata-se de uma resposta institucional para a consecução do aumento dos níveis de letramento da população portuguesa. Para mais informações ver: <http://www.planonacionaldeleitura.gov.pt/>. 
Quando falamos de literatura infantil, falamos não só do texto verbal, mas também do texto icônico. De acordo com Charréu (2012), a ilustração infantil de qualidade combina as imagens com a narratividade do texto literário, associa o potencial persuasivo do texto plástico à fluidez do texto verbal. A obra literária para crianças consiste, assim, "um feliz casamento entre as dimensões visuais e literárias da arte" (CHARRÉU, 2012, p. 3). Apoiando-se em Carol Hurst, Charréu (2012, p. 13) refere:

[...] o livro ilustrado é normalmente considerado a primeira introdução da criança à arte e que não podemos esperar que essa aproximação da criança a um fenômeno tão vibrante quanto excitante, seja facilitada por intermédio de livros medíocres ou de concepção pobre.

De facto, a relação entre o texto escrito e o texto icônico, ou seja, a relação entre o texto e as ilustrações, pressupõe uma leitura intelectual e emocional, criando experiências únicas e globais, na medida em que os dois textos são indissociáveis.

Esse contato frequente da criança com a obra de literatura infantil em contexto escolar vai fomentar e contribuir para a sua educação literária, para a sua capacidade de conhecer e manusear as convenções subjacentes à comunicação e ao texto literário, mas simultaneamente para estabelecer com ele uma relação individual, de emoção, de afeto que lhe possibilitará a leitura do texto em toda a sua plenitude e de forma significativa, como afirma Teresa Colomer (2015), numa entrevista concedida a Mello,

Así, pues, el objetivo de la educación literaria se formula como el desarrollo de la competencia en esta forma especifica de lectura e implica un aprendizaje que asocie indisolublemente la implicación del lector y el dominio de las convenciones (MELLO, 2015, p. 319, grifos no original).

Consideramos então que, antes de mais nada, a literatura (e a literatura infantil) é uma arte, mas curiosamente a literatura não se enquadra no inventário das demais artes, ao nível da educação artística. Phùng e Fendler avançam uma justificação para tal condição: 
As artes delineadas no relatório da OCDE incluem música, artes visuais, teatro, dança e multi-artes. [...] A literatura, uma forma de arte distinta que trabalha com palavras, não é geralmente citada entre as artes da educação artística. A literatura pertence às "artes da linguagem", que é tradicionalmente considerado um domínio diferente na estrutura do currículo escolar, talvez pelo significado tradicional das palavras como meio de expressão (PHÙNG; FENDLER, 2015, p. 177, tradução nossa) ${ }^{4}$

A afirmação anterior de Phùng e Fendler (2015) conduz-nos diretamente para a problemática que apresentamos neste estudo. Na escola, a literatura não é encarada como uma arte; na escola, raramente a literatura apresenta-se com valor próprio. A literatura infantil, em particular, serve múltiplos propósitos em contexto escolar e a maioria das atividades em seu redor não têm como objetivo a promoção de uma educação literária. Todavia somos apologistas da escola que percebe a literatura como uma arte, podendo haver uma relação íntima e constante entre a literatura infantil e as denominadas expressões artísticas dentro do espaço escolar e no interior da própria sala de aula.

Atualmente, na escola, em Portugal, a designada área das expressões encontra-se remetida para um segundo plano, sendo praticamente ignorada pelos docentes. Tal como afirma Sousa (2003, p. 12),

A Educação Artística não é, pois, uma concepção recente e se não tem sido posta em prática é porque os poderes políticos têm dado preferência aos valores materialistas, excluindo tudo o que não produza rentabilidade imediata.

Apesar dessa concepção que impera na sociedade e na escola, a área das expressões artísticas "é também um espaço de aprendizagens concretas e específicas que o educador deve procurar implementar com o respeito e a seriedade que qualquer área do saber deve merecer" (GODINHO; BRITO, 2010, p. 15).

Já Herbert Read, citado em Sousa (2003), crítico e estudioso dearte, era apologista de uma educação quea arte tivesse um papel fundamental, possibili-

4 "The arts outlined in the OECD report include music, visual arts, theatre, dance and multi-arts. [...] Literature, a distinct art form that works with words, is not usually named among the arts in arts education. Literature belongs to 'language arts', which is traditionally regarded a different realm in the structure of school curriculum, perhaps for the traditional significance of words as a means of expression." (PHÙNG; FENDLER, 2015, p. 177). 
tando a formação humana integral. Entende-se assim, desde há muito, a educação artística não como um leque de disciplinas de ensino das artes, estanques, mas antes implicando uma visão mais abrangente e integrada da educação e do currículo.

Um dos objetivos da educação artística consiste na defesa do direito humano à educação e à participação cultural, no sentido de promover um desenvolvimento completo e harmonioso do ser humano e uma participação na vida cultural e artística.A Unesco, no seu roteiro para a educação artística para o século XXI, alerta-nos para o fato de que "A cultura e a arte são componentes essenciais de uma educação completa que conduza ao pleno desenvolvimento do indivíduo. Por isso a Educação Artística é um direito humano universal, para todos os aprendentes." (UNESCO, 2006, p. 5).

A educação artística contribui, desse modo, para uma educação que engloba as capacidades físicas, intelectuais e criativas e permite interações mais dinâmicas e profícuas entre educação, literatura, cultura e arte. As capacidades referidas são particularmente relevantes para enfrentar os desafios da sociedade atual.

Posto isso, pensamos que as expressões artísticas são fundamentais para o desenvolvimento das crianças, para a construção da sua própria identidade, na medida em que vivenciando e experienciando diferentes papéis, para além de desencadear a imaginação, novas ideias, opiniões, sentimentos, desejos, as crianças antecipam, no fundo, situações que irão seguramente viver na realidade, no futuro, tal como afirmam Martins e Popkewitz:

A educação artística não diz respeito a competências artísticas mas sim à formação de um determinado tipo de indivíduo e ao alcançar de um futuro desejado. [...] A arte torna-se numa das mais variadas técnicas para governar a nossa própria actuação. A criança criativa é o futuro cidadão e trabalhador criativo que acreditará que o seu interior e autonomia são a expressão da sua independência, do seu sucesso ou fracasso (MARTINS; POPKEWITZ, 2015, p. 11, tradução nossa). ${ }^{5}$

As expressões artísticas, de acordo com Couto (2006), proporcionam a interiorização e a exploração dos textos literários e, assim, a vivência da língua,

5 "Art education is not about artistic competences but about the making of a certain kind of person and about achieving a desired future. [...] Art becomes one of the most variable techniques of governing one's own conduct. The creative child is the future creative citizen and worker who will believe that his/ her interiority and autonomy are the expression of his/her independence, his/ her success or failure" (MARTINS; POPKEWITZ, 2015, p. 11). 
de uma forma cativante e dinâmica, em todas as dimensões do ser da criança. Sendo assim, e partindo do princípio de que é, de fato, possível relacionar a literatura, cujo caráter é intrinsecamente transversal e integrador, e as expressões artísticas, mediante a articulação e a contextualização dos saberes. Permite-se, desse modo, o desenvolvimento de aprendizagens significativas e a formação integral das crianças, caminhando-se, paulatinamente, para o fomento de uma educação literária e de uma educação artística.

\section{Caminhos para a relação entre a educação literária e a educação artística}

O ponto de partida para esta investigação assentou na ideia da promoção da educação literária e a sua relação com as expressões artísticas, fomentando, desse modo, também, a educação artística. Assim, a questão central desta investigação era: como podemos contribuir, por meioda ação, para a promoção, nas crianças, da relação entre a literatura e as expressões artísticas, promovendo a suaeducação literária e a educação artística? Nesse sentido, enfatizou-se os seguintes objetivos específicos: dar a conhecer autores, ilustradores e textos de literatura para a infância; promover a formação do leitor literário; promover às crianças a relação entre a literatura e as expressões artísticas; promover a formação cultural e artística das crianças.

A metodologia convocada para este estudo foi a investigação-ação, dado que,de acordo com Ponte (2002), o docente investiga diariamente a sua prática, a sua relação com os alunos, encarregados de educação, entre outros, de forma a melhorar constantemente a sua ação no contexto e o contexto da sua ação. $\mathrm{Na}$ investigação-ação, o professor é entendido como um professor-investigador, como aquele que promove um ensino reflexivo, uma prática reflexiva, no sentido de questionar constantemente a sua ação com o intuito de melhorá-la, fomentando, assim, o desenvolvimento da sua prática pedagógica.

Neste estudo, utilizou-se inúmeros instrumentos que apoiaram a recolha de dados como: notas de campo e reflexões, planificações e ainda registos fotográficos, registos gráficos/produções das crianças e registos de avaliação das crianças.

A técnica de observação (participante), com observações diretas e diárias das crianças no contexto, permitiu-nos apurar os seus interesses, bem como a forma como reagiam às atividades propostas, o mesmo sucedendo com as notas de campo e as reflexões. As planificações possibilitaram compreender se as res- 
pectivas propostas iam ao encontro dos objetivos da investigação. Os registos das crianças e os registos de avaliação foram fundamentais para o processo de análise e interpretação dos dados recolhidos.

Esta investigação-ação decorreu numa escola do $10^{\circ} \mathrm{CEB}$, numa turma do $2 .^{\circ}$ ano de escolaridade, com 21 alunos, com idades compreendidas entre os sete e oito anos.

Durante a investigação-ação, inúmeras atividades foram desenvolvidas com as crianças, porém, no contexto deste artigo, apenas daremos conta de algumas. Assim, far-se-á uma abordagem pormenorizada das atividades, planificadas e executadas por nós, bem como das metodologias e materiais usados, da organização da turma e como se procedeu à avaliação das atividades mencionadas, sempre consubstanciada nas reflexões, nas notas de campo, em fotografias, nos respectivos e diversos registos, bem como nas planificações. Essas atividades espelham um trabalho que se pretende intencional e abrangente, incluindo a interligação de diferentes áreas do currículo, nomeadamente, a área da língua e da literatura e a área das expressões artísticas.

Para este estudo, para o qual se convocou a metodologia da investigação-ação, mobilizou-se também o programa de Yopp e Yopp (2006), Literature Based Reading Program. Este programa faz a apologia de que "A literatura deve estar no centro de nossos programas de letramento"6 (YOPP; YOPP, 2006, p.12, tradução nossa) e o seu desenvolvimento na sala de aula possibilita estratégias e atividades para "inspirar os alunos a se incorporarem à literatura, se envolverem com ideias em livros e expandirem seus entendimentos e respostas por meio de interações com colegas." (YOPP; YOPP, 2006, p.vii, tradução nossa). ${ }^{7}$

O Literature Based Reading Program centra-se, em termos organizativos, em três fases fundamentais: a pré-leitura, a leitura e a pós-leitura. As atividades de pré-leitura permitem às crianças, a partir dos dados paratextuais, a construção de hipóteses interpretativas, contribuindo para o desenvolvimento de competências inferenciais, mostram-lhes que as suas vivências, conhecimentos e ideias são importantes para a leitura do livro, despertam a sua curiosidade e a sua motivação para o que virá a seguir; as atividades de leitura permitem encorajar reações, a participação e a partilha e, acima de tudo, que os alunos percebam o texto e as relações que estabelecem com ele, possibilitando a construção de respostas pessoais e afetivas em relação ao texto; as atividades de pós-leitura possibilitam a reflexão sobre ideias, temas e valores presentes nas obras, con-

6 "Literature should be at the heart of our literacy programs." (YOPP; YOPP, 2006, p. 12).

7 "[...] to inspire students to bring themselves to the literature, engage with ideas in books, and expand their understandings and responses through interactions with peers."(YOPP; YOPP, 2006, p. vii). 
sentindo uma ligação entre a literatura e a vida (YOPP; YOPP, 2006; SILVA et al., 2009; BALÇA; PIRES, 2013).

Para este estudo, entre muitas outras, foram selecionadas as obras de Isabel Minhós Martins e Madalena Matoso, Quando eu nasci; e de José Jorge Letria e André Letria, Os animais fantásticos. Importa, desde logo, referir que a escolha dos livros a serem explorados partiu, inicialmente, da escolha de ilustradores, ou seja, porque falamos em expressões artísticas, nomeadamente a plástica, fez todo o sentido a escolha dos livros a partir das suas ilustrações. Ao longo do estudo tentou-se sempre aliar o texto plástico ao texto verbal, dando a conhecer às crianças o papel do ilustrador.

A primeira obra abordada neste estudo foi Quando eu nasci, da autoria de Isabel Minhós Martins, com ilustrações de Madalena Matoso, publicada pela Editora Planeta Tangerina.

Para se começar o estudo dessa obra, procedeu-se à reorganização do espaço, de forma que todas as crianças visualizassem corretamente o livro e respectivos materiais. Sendo assim, a turma ficou posicionada de modo a formar um semicírculo.

Iniciamos então as atividades de pré-leitura da obra com as crianças. Partimos do título, das ilustrações da capa e contracapa e das respectivas guardas do livro, de modo que os alunos, a partir disso, realizassem inferências sobre quais seriam eventuais temas da história.

FIGURA 1 - CAPA DO LIVRO QUANDO EU NASCI

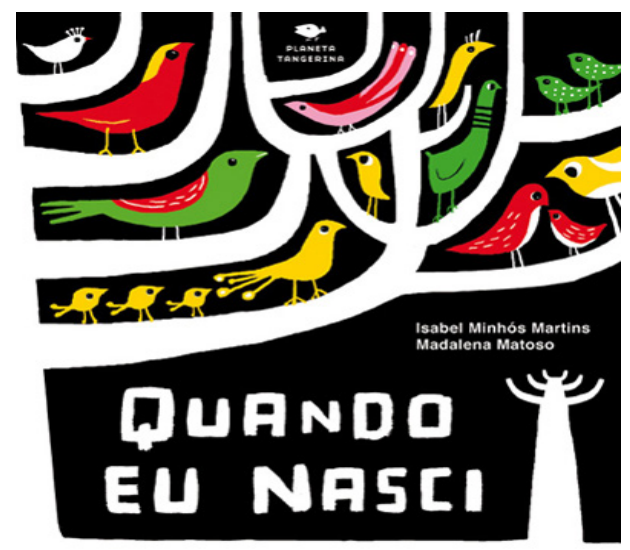

FONTE: $<$ https://www.planetatangerina.com/pt/livros/quando-eu-nasci>.

Apresentamos, a seguir, algumas das inferências efetuadas pelas crianças: 
Bruno: Está ali um passarinho, ele não sabe andar e vai aprender.

Carolina: Acho que essa árvore é a árvore da família.

Sofia: O livro fala sobre a família.

Mariana: Eu acho que é sobre o nascimento.

Filipa: Está tudo escuro porque estava na barriga da mãe e não via nada. Filipa: O livro fala sobre momentos que foi passando, desde que nasceu até crescer.

Martim: Mas nas guardas há flores e frutos. Pode ser sobre as estações do ano. (FRANCO, 2016, p. 108).

Posteriormente, atendemos ao título, à autora, à ilustradora e à editora do livro para salientar que essas já são conhecidas dos alunos, eles próprios fizeram referência a esse fato.

Em seguida, passou-se para a leitura da história propriamente dita e para a apresentação das ilustrações, nomeadamente das ainda não conhecidas. Durante a leitura da história dialogamos sobre o texto e respectivas ilustrações, antecipando a narrativa a partir delas, partilhando informação oralmente, comparando as inferências realizadas na fase da pré-leitura com o momento presente.

As atividades de pós-leitura centraram-se na expressão corporal (físico-motora) e na expressão plástica. Relativamente à expressão corporal, propusemos aos alunos que imaginassem como seria a vida dentro da barriga da mãe - silenciosa, divertida, agitada? Para a realização desta atividade foi necessário promover um ambiente adequado, revelando sua especial importância. As persianas da sala foram fechadas para garantir pouca luminosidade e, ao som de música calma e relaxante, os alunos deitaram-se no chão, fecharam os olhos e foram escutando a nossa voz. Fomos-lhes dando pistas... Os seus movimentos e expressões acompanharam aquilo que se ia dizendo. Utilizamos expressões como: "No princípio eras muito pequenino, do tamanho de um grão de areia. Ainda só eras um coração a palpitar: tum, tum ...tum, tum..."; "Estavas muito enroladinho, lá dentro, estava escuro. Sentias-te bem, muito protegido."; "Sentias também uma grande vontade de crescer e, todos os dias, crescias mais um bocadinho: os braços foram ficando cada vez maiores... as pernas também"; "Mexias devagar os dedos das mãos... Sentias a água à tua volta... Abrias e fechavas a boca, provavas a água, era fresca!"; "Às vezes ouvias a voz da tua mãe. Era uma espécie de eco que se ouvia lá dentro...”; "Ouves música, estás a dançar".

Essa atividade permitiu aos alunos despertarem memórias, desenvolverem a imaginação, a expressão corporal e, igualmente, a capacidade de concentração. 
Importa referir que essa atividade foi inspirada nas propostas de exploração para pais e educadores da Editora Planeta Tangerina ${ }^{8}$.

A outra proposta para a pós-leitura teve como base a expressão plástica. Tendo em conta a história, propôs-se aos alunos a realização de um desenho sob o título "Aquilo que eu mais quero descobrir é...". O desenho foi realizado em papel manteiga e os alunos utilizaram para tal diferentes materiais: lápis de cor, canetas hidrocor ou lápis de cera.

As crianças realizaram a avaliação desse conjunto de atividades em redor da obra literária. Colocaram-se três questões e procedeu-se ao registo escrito da voz das crianças: o que mais gostei?; o que aprendi?; o que quero aprender mais? Em seguida, registamos um exemplo das suas respostas:

Bruno: Gostei mais de ouvir a história.

Tomás: Gostei de fazer que estava na barriga da mãe.

Luana: Eu gostei mais de deitar no chão e ouvir a música.

Carolina: Quero conhecer mais autores e ilustradores.

Ana Sofia: Quero conhecer livros novos e fazer atividades de expressão plástica.

Tomás: Gostei de fazer que estava na barriga da mãe. Era como no livro. (FRANCO, 2016, p. 113).

As crianças demonstraram o gosto por ouvir histórias, o desejo de conhecer novos livros, autores e ilustradores, ao mesmo tempo que manifestaram o gosto pela realização de outras atividades, a partir de distintas formas de expressão.

Outro livro que integrou este estudo foi Os animais fantásticos, da autoria de José Jorge Letria, com ilustrações de André Letria, numa publicação da Texto Editores.

Começou-se, de novo, por reorganizar o espaço, tornando-o mais amplo e de forma que todos os alunos visualizem o livro e outros materiais utilizados.

Acentuamos que as razões para a escolha desse livro específico assentaram no fato dos alunos terem manifestado muito interesse em conhecê-lo. O livro tinha sido trazido para a sala por nós e o fato de o título e a capa, com a sua ilustração, serem extremamente apelativos fez com que as crianças desejassem conhecê-lo. Perante esse interesse manifestado por elas, decidimos que seria um dos livros a ser explorado no âmbito da presente investigação-ação.

8 Para saber mais sobre essas propostas ver: $<$ https://www.planetatangerina.com/sites/ default/files/prop_qd_nasci.pdf $>$. 
Nas atividades de pré-leitura, partindo-se de algumas das ilustrações do livro, começou-se por conversar sobre a existência ou não dos animais presentes naquela história, relacionando-os com o contexto dos alunos, e perguntamos-lhes se existiam animais fantásticos nos desenhos animados, se já tinham visto filmes ou se já tinham ouvido outras histórias protagonizadas por animais fantásticos. O diálogo avançou com questões sobre o que pensavam as crianças sobre esses animais, que animal fantástico gostariam de ser, remetendo para a sua própria personalidade, para as suas histórias de vida e experiências. Esse diálogo permitiu-nos constatar então que as crianças já possuíam concepções prévias relativamente a esses animais fantásticos.

\section{FIGURA 2 - CAPA E ILUSTRAÇÃO DO LIVRO OS ANIMAIS FANTÁSTICOS}

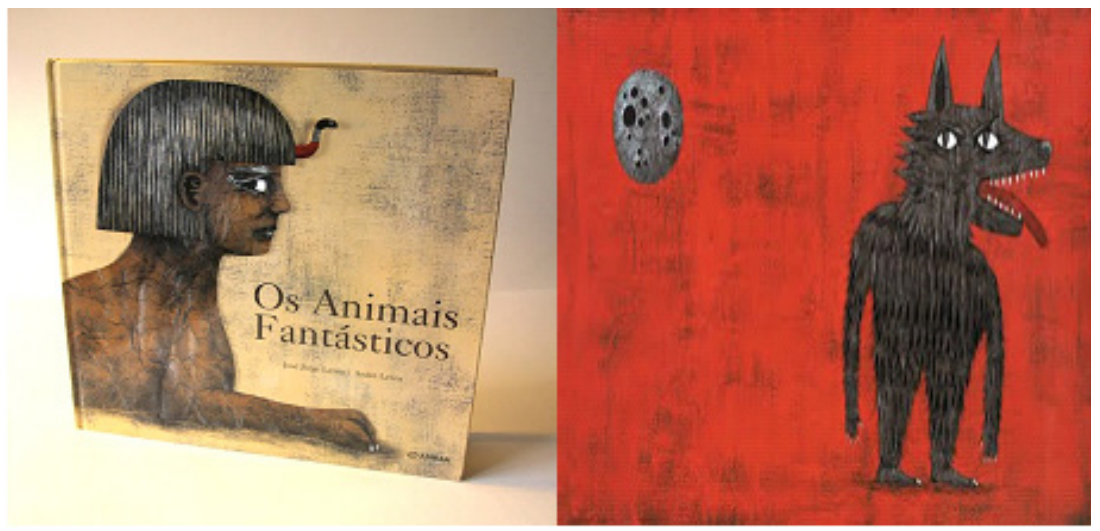

FONTE: $<$ https://andreletria.blogs.sapo.pt/4279.html>.

Apresentamos, em seguida, alguns excertos desse diálogo com as crianças:

Carolina: Estes animais não existem no mundo real. Os lobos existem ... mas aquilo não é um lobo, é um lobisomem.

Pedro: A minha mãe explicou-me. O lobisomem não é verdadeiro. Era só uma lenda.

Professora: E porque se chama lobisomem?

Pedro: É uma mistura de lobo e de homem.

Martim: Dizem que aparece nas noites de lua cheia.

Lee: Essa é a Hidra.

Sofia: E tinha nove cabeças mas agora são oito porque uma foi cortada. Parece o nosso cérebro. 
Filipa: Quando lhe cortarem todas as cabeças, ela morre.

Professora: Será, Filipa?

David: Esse é o unicórnio. Eu sei que faz magia. Euvi num livro.

Ricardo: Ai está a Fénix.

Professora: E vocês sabem o que a caracteriza?

Ricardo: Sim, renasce das cinzas.

Professora: Como é que sabes, Ricardo?

Ricardo: Tu já tinhas dito isso, no outro dia.

Professora: E são fantásticos por quê?

Pedro: Porque têm talento em várias coisas

Sara: Conheço esses animais da televisão.

Sofia: Euvi num livro que tenho em casa.

David: No Shrek há um dragão. E deita fogo como esse.

Luana: Então, a pequena sereia, a Ariel, da Disney. (FRANCO, 2016, p. 118).

Após a leitura de parte da sinopse do livro, procuramos com os alunos, recorrendo ao dicionário, algumas palavras desconhecidas para eles, procedendo-se ao registo do seu significado numa cartolina.

Posteriormente, passou-se à apresentação do livro propriamente dita: título, autor, ilustrador e editora, tendo sido as próprias crianças a identificarem esses aspetos paratextuais, que foram registrados também numa cartolina, com a sua ajuda. Relembramos ainda, como habitualmente, e com a maior facilidade, as partes principais que compõem o livro (capa, contracapa, lombada e guardas).

Continuou-se, de imediato, para a leitura de alguns dos poemas da obra, não sem antes termos explicado aos alunos que não se iria, de momento, proceder à leitura integral do livro (19 poemas), mas sim apenas de sete poemas, correspondendo estes a sete animais fantásticos. No entanto, acrescentou-se que, numa outra altura, poderíamos terminar a leitura do livro.

Durante a leitura, após lidos os primeiros versos, as crianças referiam qual o animal fantástico em causa, em cada poema. Para além disso, e uma vez que se tratava de um texto poético, as crianças acabavam por completar alguns dos versos, fazendo-se uma leitura partilhada com os alunos. No final da leitura dos poemas, identificamos o nome dos animais, a que se referem as expressões transcritas abaixo, associando, assim, a ilustração ao texto:

Sou pássaro e sou serpente (Dragão)

Sempre meio lobo, meio homem (Lobisomem)

Depois de renascer do silêncio que há nas cinzas (Fénix)

Tenho tantas cabeças que não sei qual escolher (Hidra) 
Sou cavalo e tenho asas (Pégaso)

Metade sou mulher e peixe na outra metade (Sereia)

Sou cavalo e dou bom uso a um instrumento de magia (Unicórnio). (FRANCO, 2016, p. 120).

As crianças tiveram enorme facilidade em associar o texto escrito ao texto icônico. Acredita-se que tal está relacionado com a atenção e empenho que dedicaram às atividades de pré-leitura e leitura, bem como com os seus conhecimentos prévios, como ficou bem patente em linhas anteriores.

A proposta para as atividades de pós-leitura teve como base a história, e as crianças criaram animais fantásticos, com inúmeros materiais, num trabalho desenvolvido em grupo. A cada grupo correspondia um animal fantástico, numa distribuição aleatória.

Numa mesa retangular existente na sala, as crianças tinham ao seu dispor o respectivo material: papel crepom, papel de seda, papel dobradura, tecidos, lãs. Para além disso, utilizaram lápis de cera, lápis de cor, canetas hidrocor e ainda cartolinas, cola e tesouras. No final do trabalho de expressão plástica, efetuou-se um pequeno debate em torno das atividades realizadas, focando alguns aspetos, nomeadamente: o que fizeram, com quem, como, para quê, o que sabiam, o que aprenderam e o que queriam aprender mais. As respetivas produções foram expostas, posteriormente, na biblioteca escolar.

Na sequência das atividades de pós-leitura, passou-se então para a produção de máscaras que, posteriormente, foram usadas numa pequena dramatização. Os moldes das respectivas máscaras foram realizados por nós e por dois alunos. $\mathrm{O}$ material utilizado para a confecção foi uma cartolina mais resistente.

Como foram lidos sete poemas correspondentes a sete animais fantásticos, e tal como na atividade anterior, as crianças trabalharam, de novo, em grupo, e a cada grupo correspondia uma máscara diferente. Cada aluno recortou o molde e, depois, pintou-o de acordo com os seus gostos pessoais. Finalmente, utilizou-se um elástico para segurar as máscaras.

No dia seguinte, na sala de aula, e tendo como ponto de partida os poemas dos animais fantásticos e as máscaras realizadas no dia anterior, os alunos, em grupos, realizaram uma pequena dramatização. Foi proposto às crianças que, durante um curto espaço de tempo, encarnassem esse seu animal fantástico, ou seja, iriam realizar uma breve apresentação em que mostrariam aos colegas como é que esse animal se movia e que sons produzia. Para tal, em grupo, pensaram numa pequena coreografia.

Para finalizar o trabalho sobre essa obra, elaborou-se ainda uma breve biografia do ilustrador, referindo outros livros ilustrados por ele, promovendo, 
desse modo, a intertextualidade e a intericonicidade. A pesquisa foi realizada, no dia seguinte, com pesquisa na internet.

As crianças mostraram-se extremamente interessadas e motivadas, em todos os momentos de exploração da obra, tanto na fase da pré-leitura, em que participaram ativamente no debate, mobilizando conhecimentos prévios e partilhando informações acerca dos animais fantásticos, expressando ainda sentimentos e ideias, como na fase de leitura, na qual tiveram oportunidade de fruir da leitura dos poemas e comparar inferências realizadas anteriormente e, finalmente, na fase de pós-leitura, em que foi possível expressarem-se por meio da expressão plástica e da expressão dramática.

Da avaliação das atividades foi realizado um balanço extremamente positivo. As crianças referiram que o que gostaram mais foi "ouvir a história e fazer o teatro", "fazer atividades destas", "foi muito divertido" (FRANCO, 2016, p. 124).

\section{Conclusões}

O presente estudo, desenvolvido com crianças que frequentavam o $1 .^{\circ}$ CEB e para o qual convocamos a metodologia da investigação-ação, tinha como objetivo fomentar nas crianças a educação literária e a sua relação com as expressões artísticas, promovendo, também, a educação artística.

Tentamos também com este estudo chamar a atenção para uma situação muito comum nas escolas portuguesas: a pouca importância conferida à área das expressões e o não encarar a literatura como uma arte, o não atribuir à literatura um valor próprio.

A literatura (e a literatura infantil), bem como as expressões artísticas, contribuem para a formação integral da criança, dado o seu enorme potencial humanizador. Com este estudo procuramos a possibilidade de se olhar para a articulação entre duas áreas curriculares consideradas distintas, mas afinal muito próximas, estimulando a ligação entre a obra literária e as expressões artísticas, num trabalho que pretendia colocar a ênfase no desenvolvimento de competências nas crianças que lhes permitissem uma leitura plena, com significado, intelectual e emocional da obra literária, por meio da vivência das expressões artísticas.

Assim, o estudo foi desenvolvido com várias obras de literatura infantil, com particular destaque para as suas ilustrações, convocando a expressão plástica, a expressão dramática e a expressão motora, entre outras. 
A partir da observação participante e dos vários instrumentos de recolha de dados, conseguimos chegar a algumas conclusões neste estudo. As crianças envolvidas no estudo mostraram sempre, ao nível das atitudes, empenho, participação, entusiasmo, interesse, motivação nas atividades propostas e desenvolvidas. Ao nível das competências, foi possível perceber que as crianças desenvolveram as suas competências literária e enciclopédica, estimularam a competência inferencial, fortaleceram as competências linguística, comunicativa e pragmática e aprofundaram as competências visuais, performativas e experimentais.

Sendo assim, consideramos que as crianças conheceram autores, ilustradores e textos de literatura infantil, estabelecendo relações entre este produto cultural de elevada qualidade, que é a obra literária, e as expressões artísticas; consideramos ainda que foi promovida a formação do leitor literário bem como a formação cultural e artística das crianças.

\section{REFERÊNCIAS}

AGUIAR E SILVA, Vítor Manuel. Teoria e Metodologia Literárias. Lisboa: Universidade Aberta, 2004.

AZEVEDO, Fernando. Literatura infantil, recepção leitora e competência literária. In: AZEVEDO, Fernando (Orgs.). Língua materna e literatura infantil: elementos nucleares para professores do ensino básico. Lisboa: Lidel, 2006. p. 11-32.

BALÇA, Ângela; PIRES, Maria Natividade. Literatura infantil e juvenil: formação de leitores. Lisboa: Santillana, 2013.

CASTRO, Marcela. La lectura de ficción enseña a ler. El Monitor de la Educación, v. 2, n. 4, p. 1-4, nov. 2001. Disponível em: <http://servicios.educarm.es/templates/portal/ ficheros/websDinamicas/154/leercomprender.pdf>. Acesso em: 23 jan. 2018.

CHARRÉU, Leonardo. Arte visual contemporânea, ilustração e literatura para a infância: fazendo conexões entre mundos criativos. Revista Digital do Laboratório de Artes Visuais, Santa Maria: Centro de Educação, Universidade Federal de Santa Maria, n. 9, p. 1-20, 2012. Disponível em: <https://periodicos.ufsm.br/revislav/article/view/6295>. Acesso em: 22 jan. 2018.

COUTO, José Manuel. Explorando as potencialidades da língua e da literatura infantil e juvenil. Vivenciar a língua: a Literatura Infanto-Juvenil e as Expressões artísticas. In: AZEVEDO, Fernando (Orgs.). Língua materna e literatura infantil: elementos nucleares para professores do ensino básico. Lisboa: Lidel, 2006. p. 245-282. 
FRANCO, Mafalda. Prática de Ensino Supervisionada em Pré-Escolar e Ensino do $1 .^{\circ}$ Ciclo do Ensino Básico: Educação Literária - A Literatura para a Infância e as Expressões Artísticas. 2016. Tese (Mestrado em Educação Pré-Escolar e em Ensino do 1. ${ }^{\circ}$ Ciclo do Ensino Básico) - Universidade de Évora, Évora. 2016. Disponível em: $<$ https://dspace. uevora.pt/rdpc/handle/10174/18530>. Acesso em: 04 jan. 2018.

GODINHO, José Carlos; BRITO, Maria José. As artes no Jardim de Infância. Lisboa: DGIDC - Ministério da Educação, 2010.

LETRIA, José Jorge; LETRIA, André. Os animais fantásticos. Lisboa: Texto Editores, 2011.

MARTINS, Catarina; POPKEWITZ, Thomas. The "Eventualizing" of Arts Education. Sisyphus Journal of Education, Lisboa: Universidade de Lisboa, v. 3, n. 1, p. 7-17, dez. 2015. Disponível em: < http://revistas.rcaap.pt/sisyphus/article/view/7727>. Acesso em: 10 jan. 2018.

MARTINS, Isabel Minhós; MATOSO, Madalena. Quando eu nasci. Carcavelos: Editora Planeta Tangerina, 2007.

MELLO, Cláudio. Entrevista a Teresa Colomer sobre Educación Literaria. Via Atlântica, São Paulo: Universidade de São Paulo, n. 28, p. 313-326,dez. 2015. Disponível em: <http://www.revistas.usp.br/viaatlantica/article/view/100870/107097>. Acesso em: 19 jan. 2018.

PHÙNG, Thanh; FENDLER, Lynn. A critique of knowledge-based arts education: ars gratia artis through rancière's aesthetics. Sisyphus Journal of Education, Lisboa: Universidade de Lisboa, v. 3, n. 1, p. 172-191, dez. 2015. Disponível em: <http://revistas. rcaap.pt/sisyphus/article/view/7727>. Acesso em: 10 jan. 2018.

PONTE, João Pedro. Investigar a nossa própria prática. In: GRUPO DE TRABALHO DE INVESTIGAÇÃO (Orgs). Reflectir e investigar sobre a prática profissional. Lisboa: Associação dos Professores de Matemática, 2002. p. 5-28.

SILVA, Gisela; SIMÕES, Rita; MACEDO, Teresa; DIOGO, Américo Lindeza; AZEVEDO, Fernando. Ler para entender: Língua Portuguesa e formação de leitores. Porto: Trampolim,2009.

SOUSA, Alberto. Educação pela arte e artes na educação: bases psicopedagógicas. v. 1. Lisboa: Instituto Piaget, 2003.

UNESCO. Roteiro para a educação artística: desenvolver capacidades criativas para o século XXI. Lisboa: Touch Artes Gráficas, 2006.

YOPP, Hallie; YOPP, Ruth. Literature based reading activities. Boston: Pearson, 2006.

Texto recebido em 08 de junho de 2018.

Texto aprovado em 08 de agosto de 2018. 